\title{
Estelle Doudet, Chrétien de Troyes
}

\section{Mariagrazia Ricci}

\section{(2) OpenEdition}

\section{Journals}

\section{Édition électronique}

URL : http://journals.openedition.org/studifrancesi/5845

DOI : 10.4000/studifrancesi.5845

ISSN : 2427-5856

\section{Éditeur}

Rosenberg \& Sellier

\section{Édition imprimée}

Date de publication : 1 mai 2011

Pagination : 142-143

ISSN : 0039-2944

\section{Référence électronique}

Mariagrazia Ricci, «Estelle Doudet, Chrétien de Troyes », Studi Francesi [En ligne], 163 (LV | I) | 2011, mis en ligne le 30 novembre 2015, consulté le 13 janvier 2021. URL : http://journals.openedition.org/ studifrancesi/5845; DOI : https://doi.org/10.4000/studifrancesi.5845

\section{Ce document a été généré automatiquement le 13 janvier 2021.}

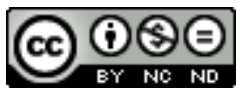

Studi Francesi è distribuita con Licenza Creative Commons Attribuzione - Non commerciale - Non opere derivate 4.0 Internazionale. 


\title{
Estelle Doudet, Chrétien de Troyes
}

\author{
Mariagrazia Ricci
}

\section{RÉFÉRENCE}

ESTELLE DOUDET, Chrétien de Troyes, Paris, Tallandier, 2009, pp. 363.

1 Chrétien de Troyes est sans aucun doute l'un des écrivains médiévaux les plus étudiés aux $\mathrm{xx}^{\mathrm{e}}-\mathrm{xxI}^{\mathrm{e}}$ siècles, mais, nonobstant les très nombreuses recherches dont il a fait l'objet, est-ce qu'on peut affirmer de le connaitre vraiment? C'est la question qu'E.D. pose dans l'Introduction à son ouvrage, pour répondre que ce nom de Chrétien (de Troyes) est tout ce qui nous reste de lui à travers les vers de ses romans. C'est pourquoi une enquête supplémentaire sur l'époque à laquelle il a appartenu et sur l'ensemble de ses œuvres paraît toujours utile: tout moderne qu'il puisse nous paraître, Chrétien demeure en effet le fils de son temps, et le milieu dans lequel il a vécu est bien le cadre naturel de ses romans.

2 E.D. prend d'abord en considération les problèmes liés à la biographie du poète, tels que le nom, la provenance et la langue, en présentant les différentes hypothèses formulées au fur et à mesure par les critiques, sans tout de même pouvoir leur donner une solution définitive (première partie: Crestiens de Troies, la construction d'une identité, pp. 13-65).

3 La deuxième partie (L'homme des cours. Écrire au XII siècle, pp. 67-130) est consacrée au système éducatif de la seconde moitié du XII ${ }^{\mathrm{e}}$ siècle, au cadre social et culturel de la cour de Champagne et à la définition de notions culturelles telles que féodalité et courtoisie, qui demeurent fondamentales pour comprendre la production de Chrétien.

Les troisième et quatrième parties (Les défis du roman (1170-1176) pp. 131-196 et Maturité d'un moderne (1177-1183?), pp. 197-269) proposent une analyse des romans de Chrétien, présentés en suivant l'ordre chronologique de composition: E.D. montre combien ces textes, tout en reflétant l'époque dans laquelle ils ont été rédigés, sont aussi représentatifs d'une vision personnelle du monde et évoluent avec celle-ci; d'autre part, le roman, genre nouveau au $\mathrm{XII}^{\mathrm{e}}$ siècle, situé donc en dehors des contraintes 
imposées par la tradition littéraire, est pour Chrétien le moyen le plus adapté pour déployer un regard distancié et ironique sur la réalité contemporaine.

Dans la cinquième section («Toujours sera en mémoire». L'héritage de Chrétien de Troyes (XIII ${ }^{e}$ - XXI ${ }^{e}$ siècles), pp. 271-325), E.D. propose enfin un aperçu sommaire de l'héritage du romancier: du Moyen Âge à l'époque moderne, un peu partout en Europe, Chrétien est réécrit, «continué», réinventé et copié, mais aussi irrémédiablement méconnu, voire oublié. En France ses œuvres seront édités à partir de la fin du XIX siècle (Foerster, Micha), mais la critique lui consacrera son attention surtout à partir de la seconde moitié du $\mathrm{xx}^{\mathrm{e}}$ siècle après la parution du travail magistral et fondateur de Jean Frappier.

Le livre d'E.D. comprend aussi une série d'annexes: une carte résumant la géographie des romans de Chrétien; plus intéressante dans l'optique envisagée par l'A., une "Chronologie des $\mathrm{XII}^{\mathrm{e}}$ et XIII ${ }^{\mathrm{e}}$ siècles» qui réunit les événements historiques et culturels, ainsi que les dates connues ou hypothétiques de la vie de Chrétien; enfin, la généalogie des comtes de Champagne au XII ${ }^{\mathrm{e}}$ siècle.

7 La bibliographie n'est évidemment pas exhaustive, comme le déclare l'A. elle-même, qui renvoie au site Arlima et aux bibliographies de D. Kelly (1976 et supplément 2002): seules sont données ici les références des ouvrages cités. Nous nous permettons néanmoins une ou deux remarques de détail. Pour ce qui concerne notamment la réception des œuvres de Chrétien, on aurait souhaité une mise à jour des éditions critiques: l'Érec et le Cligès en prose ont été édités par Maria Colombo Timelli respectivement en 2000 et 2004 (Genève, Droz, TLF); le Chevalier de la Charrette (version dérimée) par David Hult («Romance Philology», 57, 2004; l'édition par Annie Combes est encore plus récente: Champion, 2009); enfin, on est quelque peu surpris de voir attribuer la Bibliothèque Universelle des Romans au comte de Tressan seul (cf. la Bibliographie, p. 344). 